\title{
Graphene nanoplatelets coating for corrosion protection of aluminum substrates
}

\author{
Fatima Z. Bouanis, ${ }^{1,2 *}$ Prisca Moutoussammy, ${ }^{1,2}$ Ileana Florea, ${ }^{2}$ Nadia \\ Dominique, ${ }^{1}$ Thierry Chaussadent, ${ }^{1}$ and Didier Pribat ${ }^{1}$ \\ ${ }^{1}$ University Paris Est, IFSTTAR, Boulevard Newton, 77420 Champs-sur-Marne, France. \\ ${ }^{2}$ Laboratory of Physics of Interfaces and Thin Films, UMR 7647 CNRS/ Ecole Polytechnique \\ Palaiseau-France.
}

\section{Keywords:}
A. Graphene nanoplatelets
B. corrosion protection
C. sodium chloride
D. aluminum substrate

${ }^{1}$ University Paris Est, IFSTTAR, Boulevard Newton, 77420 Champs-sur-Marne, France.

* Corresponding author at: University Paris Est, IFSTTAR, Boulevard Newton, 77420 Champs-sur-Marne, France

Tel: +33 (0) 1693343 85, E-mail address: fatima.bouanis@ ifsttar.fr (Fatima Zahra Bouanis)

\begin{abstract}
In this work, we study the properties of re-assembled graphene nanoplatelets as an effective anticorrosion coating for aluminum (Al) substrate in 0.5 M Sodium Chloride $(\mathrm{NaCl})$ at room temperature $\left(30^{\circ} \mathrm{C}\right)$. Scanning and Transmission Electron Microscopy (TEM) as well as Raman spectroscopy reveal the high quality multilayer graphene nanoplatelets. The modifications of the corrosion resistance characteristic were investigated by Open Circuit Potential (OCP), followed by electrochemical tests such as potentiodynamic polarization (Tafel curves) and Electrochemical Impedance Spectroscopy (EIS). The electrochemical results show that the graphene nanoplatelets provide effective resistance against the corrosive medium
\end{abstract}


during the two weeks of immersion in the saline medium. Scanning Electron Microscopy (SEM), Raman spectroscopy and Energy Dispersive X-ray (EDX) studies carried out after immersion in the corrosive medium confirm that a graphene-coated aluminum surface is well protected compared to an uncoated substrate.

\section{Introduction}

The corrosion of metal structures is recognized as one of the most serious issue in the modern societies as it results in the loss of more than one hundred billions of dollars in damage each year [1]. Intense efforts have been made to find protective coatings that inhibit the process of metal corrosion. Recently, graphene has been considered as a highly promising new material for corrosion-inhibiting coatings [2], because of its impermeability and hydrophobic properties $[3,4]$, which create a barrier against gases and liquids in a corrosive environment. Graphene is considered as an environmentally friendly low cost coating, which is chemically and thermally stable [5,6], as well as inert under different atmospheres [7]. Single and multilayer graphene have the potential to form ultrathin coatings which do not alter the properties of the underlying material $[2,8-9]$. All these properties make graphene an attractive candidate for the protection against corrosion.

Many studies have reported the effectiveness of graphene films in reducing corrosion. First, Chen et al. [8] have demonstrated that graphene grown by chemical vapor deposition (CVD) can inhibit the oxidation of metallic substrates of $\mathrm{Cu}$ and $\mathrm{Cu} / \mathrm{Ni}$ alloy in air or in $30 \%$ hydrogen peroxide medium. In a closely related study, Prasai et al. [2] reported a similar anticorrosion effect of CVD-grown graphene, as well as of mechanically transferred multilayer graphene in an aerated $\mathrm{Na}_{2} \mathrm{SO}_{4}$ solution. These results were also confirmed by other studies [10-14], which concluded that graphene films grown directly on the metal by CVD present higher anticorrosion performance than transferred graphene coatings. Indeed, the transfer process is known to reduce 
homogeneity over large areas and thus is expected to drastically impact the impermeability as well as reduce homogenous covering of the surface to be treated. However, the synthesis of graphene by $\mathrm{CVD}$ requires specific catalytic substrates $(\mathrm{Cu}, \mathrm{Ni} \ldots)$ and high temperature (> $\left.900^{\circ} \mathrm{C}\right)$, which is not suitable for many metals $(\mathrm{Al}, \mathrm{Mg} \ldots)$. Moreover, graphene produced by CVD is probably not that much an economical coating for corrosion application. Moreover, the graphene synthesis temperature (say $>900^{\circ} \mathrm{C}$ for most CVD processes) is not compatible with direct growth on $\mathrm{Al}$ substrates. Research has therefore focused on finding new low temperature methods of graphene deposition upon different metal surfaces. Several studies have demonstrated graphene protection of aluminum [14-17], steel [18, 19], and magnesium [20] substrates by using many different processes, including graphene oxide [16,18], polymer/graphene mixtures $[21,22]$, etc. However, mechanically exfoliated graphene coatings have rarely been discussed.

To the best of our knowledge, the study of mechanically exfoliated graphene as a passivation layer to protect aluminum (Al) surfaces has not been reported yet. It was pointed-out in a recent study that graphene grown by CVD and transferred from a $\mathrm{Cu}$ substrate to an $\mathrm{Al}$ substrate protects less the $\mathrm{Al}$ substrate compared to the $\mathrm{Cu}$ substrate [23]. It was shown that the passivating $\mathrm{Al}$ oxide film breaks up after a long immersion time in a sodium chloride solution, which promotes the electrochemical corrosion process [23]. Consequently, it is believed that only a high quality graphene with uniform coverage can suppress ion diffusion through the nanoscopic defect channels of graphene and prevent the formation of a local galvanic cell. In the present work, we study the effectiveness of mechanically exfoliated graphene as anticorrosion layers on $\mathrm{Al}$ surface. $\mathrm{Al}$ was chosen as the substrate since it is used in many industries such as aerospace, marine, automobile, construction industries, etc. Although Al is usually selfpassivated by its native oxide, the surface of $\mathrm{Al}$ and its alloys is easily corroded by chloride 
ions $\left(\mathrm{Cl}^{-}\right)$in neutral aqueous solutions [24]. There is therefore a need to explore new alternatives in order to extend the lifetime of $\mathrm{Al}$ and its alloys.

Here, Raman spectroscopy, scanning (SEM) and transmission (TEM) electron microscopies, as well as energy-dispersive X-ray spectroscopy (EDX) were used to assess the quality and the number of layers of graphene on the surface of Al before and after immersion in a corrosive medium. The corrosion behavior was evaluated by open circuit potential (OCP), potentiodynamic polarisation and electrochemical impedance spectroscopy (EIS) measurements in $0.5 \mathrm{M} \mathrm{NaCl}$ solutions at room temperature $\left(30^{\circ} \mathrm{C}\right)$. The results were compared to corresponding untreated $\mathrm{Al}$ substrates (pristine $\mathrm{Al}$ foils).

\section{Experimental}

\section{Graphene nanoplatelets films}

Commercial Al foils coated with graphene nanoplatelets films were purchased from "Graphene Supermarket" and used as received. The purity of the Al foils underneath the graphene coating was $99 \%$. The graphene nanoplatelets forming the protective films are obtained by mechanical exfoliation of graphite. The uncoated $\mathrm{Al}$ foils with a thickness of about $16 \mu \mathrm{m}$ and with a purity of $99 \%$ were purchased from Goodfellow.

\section{Characterization techniques}

Raman spectra were recorded using a high-resolution confocal Raman microscope (Labram HR800; HORIBA Jobin Yvon, France) through a 100× microscope objective (NA=1) in order to demonstrate the quality and the presence of graphene before and after immersion in the corrosive medium. Micro-Raman mapping was performed in high resolution mode, using a laser excitation of $\lambda=532 \mathrm{~nm}$ with $10 \mathrm{~s}$ acquisition time and 5 accumulations per spectrum. The number of gratings in the Raman spectrometer was 600 grooves per mm. Raman mapping was performed on $15 \mu \mathrm{m} \times 15 \mu \mathrm{m}$ areas with a step size of $0.5 \mu \mathrm{m}$. Scanning Electron Microscopy 
(SEM) observations were carried out with a HITACHI S 4800 electron microscope. Further, to investigate the chemical state of the graphene coatings, energy dispersive X-ray spectroscopy (EDX) analyses (Thermo Ultra Dry) have been performed. The analysis of uncoated Al substrates and graphene-coated $\mathrm{Al}$ substrates were performed before and after immersion in $0.5 \mathrm{M}$ sodium chloride $(0.5 \mathrm{M} \mathrm{NaCl})$. The HR-TEM analyses were performed using an FEITitan electron microscope operating at 60,80 and $300 \mathrm{kV}$ and equipped with a Cs image corrector. For the graphene observations, an operating voltage of $80 \mathrm{kV}$ was used in order to avoid any beam-induced damage. Prior the TEM observations of the graphene, a preliminary step was mandatory, consisting in transferring the graphene from the substrate surface onto $\mathrm{Cu}$ mesh TEM grids. This has been done using a polymethyl methacrylate (PMMA) transfer method [25]. In order to protect the graphene and facilitate its transfer, the PMMA was spincoated on the graphene-coated $\mathrm{Al}$ foils at $3000 \mathrm{rpm}$ for $40 \mathrm{~s}$, followed by drying at $100^{\circ} \mathrm{C}$ for 5min. Then, the $\mathrm{Al}$ foil was etched in $\mathrm{NaOH}(1 \mathrm{~mol} / \mathrm{l})$ during $1 \mathrm{~h}$. The graphene/PMMA was removed and placed into deionized (DI) water baths. After rinsing several times with DI water, the PMMA/graphene was carefully deposited onto the TEM grid. Finally, the TEM grids were dried at $100^{\circ} \mathrm{C}$ during $24 \mathrm{~h}$ and then the PMMA was dissolved in acetone.

\section{Electrochemical measurements}

We investigated the electrochemical properties of graphene nanoplatelets on Al substrates in $0.5 \mathrm{M} \mathrm{NaCl}$ solution. Uncoated $\mathrm{Al}$ substrates were used as a reference. The samples were first rinsed with acetone and then rinsed again with deionized water and were finally dried under N2. A BioLogic SP-300 Modular Re-search Grade Potentiostat/Galvanostat/FRA together with an EC-LAB software 10.37 computer program were employed to investigate the electrochemical corrosion behavior of the coatings. Electrochemical measurements (potentiodynamic polarization and EIS tests) were performed in a conventional three-electrode cell containing $0.5 \mathrm{M} \mathrm{NaCl}$ as the electrolyte. The electrochemical cell set-up consisted of 1 
$\mathrm{cm}^{2}$ area of the graphene- coated $\mathrm{Al}$ as the working electrode, a platinum foil as the auxiliary electrode and a saturated calomel electrode (SCE with $0.242 \mathrm{~V}$ vs. NHE) as the reference electrode. All the experiments were performed at room temperature. The open circuit potential (OCP) was monitored for $30 \mathrm{~min}$, in order to confirm the three-electrode cell stability with time before the electrochemical tests. The potentiodynamic polarization measurements were carried out at a scan rate of $0.5 \mathrm{mV} / \mathrm{s}$ in the scan range of $-250 \mathrm{mV}$ to $+250 \mathrm{mV}$ vs. SCE. The EIS spectra were measured in the frequency range of $10 \mathrm{mHz}$ to $100 \mathrm{kHz}$, recording 10 points per decade of frequency, by applying a sinusoidal potential wave at OCP with an AC amplitude of $10 \mathrm{mV}$. The impedance data were interpreted on the basis of equivalent electrical circuits using the ZView version 2.8 program for fitting the experimental data.

\section{Result and discussion}

\section{Structural analysis of graphene coating}

The Raman spectra were taken at several zones on the graphene films over Al substrates in order to obtain more information about the quality and the number of graphene nanoplatelets layers. Fig. 1 shows the Raman mapping of the graphene films deposited on Al substrates using an excitation wavelength of $532 \mathrm{~nm}$. The presence of three peaks is noted. More precisely, (i) the peak located at $\sim 1350 \mathrm{~cm}^{-1}$ corresponds to the D band of graphitic carbon species, which is associated with the amount of defects in the crystalline structure of graphene layers. The low intensity of this disorder-induced D band confirms that the graphene films exhibit a low density of defects [26]; those defects are probably mainly located at the edges of the graphene flakes (dangling bonds); (ii) a highly intense $\mathrm{G}$ band, corresponding to the optically allowed $\mathrm{E}_{2 \mathrm{~g}}$ phonons at the Brillouin zone center, occurs at $\sim 1580 \mathrm{~cm}^{-1}$ and represents planar vibrations of carbon atom in the crystalline graphitic material [27]. The intensity ratio of the D band over the G band $\left(I_{D} / I_{G}\right)$ is $\sim 0.15$; (iii) a $2 \mathrm{D}$ band located at $\sim 2700 \mathrm{~cm}^{-1}$, which is a hallmark for the 
presence of graphene. It has been reported that the $I_{G} / I_{2 D}$ ratio varied from $\sim 0.5$ to values larger than 1 for single layer to multilayer graphene films, respectively [27, 28]. In the present case, the $I_{G} / I_{2 D}$ ratio of $\sim 2.01$ clearly indicates five or six layers of graphene coating on $\mathrm{Al}[27,28]$. The number of graphene layers is further verified by TEM analysis (see below).

Fig.2 shows the TEM micrographs of graphene nanoplatelets after transfer onto the TEM holey carbon grid. According to the TEM observations the graphene flakes appear to cover several square micrometers (Fig. 2 (a)). We observe the presence of different folding on the surface, in agreement with the scanning electron microscope observations (see below). The number of graphene layers is four to six (Fig. 2 (b) and Fig. 2 (c)), which is in agreement with the Raman results (Fig.1). Multilayer graphene coatings without having strong adhesion to the metal substrates can effectively function as inert protective layers preventing diffusion of aqueous solutions [8]. Selected area electron diffraction (fig. 2(d)) indicates the crystalline structure of the graphene nanoplatelets.

In order to obtain additional information about the uniformity of the graphene coating on the Al surface, scanning electron microscope (SEM) observations were performed. Fig. 3 shows SEM images of an Al foil coated with graphene nanoplatelets before immersion in the corrosive medium. As can be seen from this figure, graphene is present all over the selected area, with apparently different levels of thickness. We can also see the presence of folds, wrinkles and edges in the graphene layers, which have been previously reported [29].

Electrochemical measurements and corrosion inhibition performance

To demonstrate the potential of graphene as a protection layer for Al substrates in a saline environment, electrochemical measurements were performed. The saline environment was chosen as the electrolyte because of its high aggressive behavior. Actually, it is well known 
that $\mathrm{Cl}^{-}$ions can disrupt the protective surface layer of the majority of metal surfaces inducing the local formation of soluble salts $[23,24]$.

The open circuit potential (OCP) was monitored for $30 \mathrm{~min}$ for $\mathrm{Al}$ and graphene- coated $\mathrm{Al}$ in order to get a stable potential with time before carrying out the corrosion tests ( see Figure 4(a)). We observe that OCP measurements present slight fluctuation (less than $4 \mathrm{mV}$ ), which confirms the relative stability of the system during this time. In order to obtain more information about the stability of the system over a long period of time, the OCP measurements were performed for 2 weeks. Fig. 4(b) shows the OCP measurement results of Al substrates and graphene-coated $\mathrm{Al}$ substrates during 2 weeks of immersion in the $0.5 \mathrm{M} \mathrm{NaCl}$ solution. Each data point is an average of 3 to 5 tests under the same conditions. Two behaviors can be observed from Fig.4(b). First, OCP presents some fluctuation during 175h, second, after this stage, it becomes more positive and then evolves to stable values. Moreover, the potential of the graphene-coated $\mathrm{Al}$ is more positive than that of the uncovered $\mathrm{Al}$ substrate; this indicates either a stable passivation film for the graphene-coated $\mathrm{Al}$ foil or an effect of the high potential of graphene or both, without it being possible to discriminate. Nevertheless, this result is consistent with the findings of Stankovic' et al. [23] with $\mathrm{E}_{\mathrm{ocp}}$ values for graphene-coated Al even higher in our experiment. At this point, we note that in ref. 23, most reported results correspond to Al coated with 3 layers of transferred CVD-grown graphene.

Polarization curves were used to determine the corrosion rate of $\mathrm{Al}$ and graphene-coated $\mathrm{Al}$ samples. We first establish the OCP in order to stabilize the anodic and cathodic processes. Fig. 5 shows the Tafel polarization curves of uncoated $\mathrm{Al}$ and graphene-coated $\mathrm{Al}$ substrates after immersion during $264 \mathrm{~h}$ in the corrosive medium at $30^{\circ} \mathrm{C}$. It was previously reported that the anodic dissolution rate of $\mathrm{Al}$, i.e., $\mathrm{Al} \rightarrow \mathrm{Al}^{3+}+3 \mathrm{e}^{-}$at a given potential is estimated by the anodic current, while the cathodic current densities determine the rate of the oxygen reduction reaction, namely $2 \mathrm{H}_{2} \mathrm{O}+\mathrm{O}_{2}+4 \mathrm{e}^{-} \rightarrow 4 \mathrm{OH}^{-}$. The data were fitted by "Origin lab" and then the 
results were confirmed by "linear regression". In order to obtain linear fit, the part of the curve at large over potential was excluded. The values of associated electrochemical parameters such as corrosion potential $\left(E_{c o r r}\right)$ and corrosion current density $\left(I_{c o r r}\right)$, of uncoated and graphenecoated Al, are presented in Table 1. As shown in Fig.5 and data in Table 1, the corrosion potential $E_{c o r r}$ value of the graphene-coated sample $(672 \mathrm{mV})$ shifts to less negative values (by nearly $20 \mathrm{mV})$ as compared to the uncoated $\mathrm{Al}(-690 \mathrm{mV})$, suggesting that the graphene coating acts as a corrosion-resistant barrier for the Al surface. Furthermore, the anodic current densities of the graphene-coated $\mathrm{Al}$ substrate were lower than uncoated sample (Fig. 5) indicating that the graphene coating strongly reduces the $\mathrm{Al}$ dissolution. These results are consistent with those from literature $[14,16]$.

The corrosion current density $i_{\text {corr }}$ value of graphene-coated $\mathrm{Al}(0.07 \mu \mathrm{A})$ is significantly three times lower than $i_{\text {corr }}$ value of uncoated $\mathrm{Al}(0.2 \mu \mathrm{A})$, suggesting that graphene suppresses the corrosion reaction by limiting the diffusion of chloride ions, oxygen and water to the substrate. This is in contrast with the $i_{c o r r}$ values reported by Stankovic' et al. [23], where an increase in the corrosion rate as a result of multilayer graphene coating transferred onto Al sample was reported, suggesting a high corrosion susceptibility of the graphene-coated Al.

We recall however that in ref. 23 there were 3 graphene layers instead of 4 to 6 in our situation. Raman spectra recorded after corrosion tests indicate that the initial (Fig. 1) and final Raman spectra (Fig. 5 (b)) of the graphene-coated $\mathrm{Al}$ are identical and its surface is undamaged, which suggests that the graphene coating provides efficient protection of $\mathrm{Al}$ substrate.

In order to better understand the behavior of graphene-coated Al samples, their corrosion resistance performance has been monitored by EIS measurements. The obtained EIS data (also called "Nyquist plot") of uncoated and coated Al substrates after $312 \mathrm{~h}$ of immersion in the corrosive medium are given in Fig. 6. The imaginary component $\left(\mathrm{Z}_{\mathrm{imag}}\right)$ of the impedance is plotted as a function of the real component $\left(\mathrm{Z}_{\text {real }}\right)$ on a linear scale. The total diameter of the 
semicircle in the Nyquist plot is a measure of the corrosion resistance; in other words, the bigger the semicircle, the better the anti-corrosion performance [13]. In Fig. 6, the semicircle diameter of coated $\mathrm{Al}$ is much longer than that of the uncoated sample, showing much better anticorrosion property.

In order to get more insight into the electrochemical phenomena that lead to this improvement, an equivalent electrical circuit (EEC) $[16,23]$ was used to analyze the electrochemical data (fig. 7). In this study, the impedance of two interfaces metal/electrolyte and surface coating/electrolyte were analyzed. Due to the obtained two time constants of EIS response, the EEC is presented by $\mathrm{R}(\mathrm{Q}(\mathrm{R}(\mathrm{QR})))$ by using circuit description code (CDC) in Fig. 7. In order to take into account the inhomogeneity of structural or interfacial origin, the constant phase element $(\mathrm{CPE})$ or $(\mathrm{Q})$ was introduced in the circuit to give a more accurate fit [30]. The impedance of the CPE is defined as: $Z_{C P E}=A^{-1}(i \omega)^{-n}$, where

" $\omega$ " is the angular frequency, " $A$ " the CPE constant, " $\mathrm{i}^{2}=-1$ " is the imaginary number and " $\mathrm{n}$ " the CPE power $(0 \leq n \leq 1)$. One can find that for " $n=1$ " the CPE is a pure capacitance.

Briefly, in the case of graphene coating, the equivalent circuit consists of the electrical solution resistance $\left(R_{S}\right)$ (the resistance of the electrolyte between the working electrode and auxiliary electrode), the constant phase element $C P E_{1}$ related to the capacitance of the coating, which is in parallel with the pore/crack resistance $R_{1}\left(C P E_{1}\right.$ and $R_{1}$ are related to the properties of the graphene coating and the electrolyte/graphene coating interface reactions) and the $C P E_{2}$ in parallel with the resistance $R_{2}$, which corresponds to the oxide layer present under the graphene coating. The corrosion resistance is the mathematical sum of $R_{l}$ and $R_{2}$ [13]. In the case of the uncoated $\mathrm{Al}$ substrate, $C P E_{1}$ represents the constant phase element, which is in parallel with the resistance $R_{1}$ corresponding to the oxide layer on the $\mathrm{Al}$ substrate, while $C P E_{2}$ is related to double layer capacitance, which is in parallel with the charge transfer resistance $\left(R_{2}\right)$. The data are found to be sufficiently well fitted within the limits of experimental error and 
reproducibility, which confirms that fig. 7 is the appropriate EEC to represent the electrochemical processes. Based on fitted parameters, the total corrosion resistance of graphene is 38 (i.e., $15+22$ ) $\mathrm{k} \Omega \mathrm{cm}^{2}$, almost 4 times that of uncoated $\mathrm{Al}$ which is just $9 \mathrm{k} \Omega$ $\mathrm{cm}^{2}$. The $\mathrm{CPE}_{2}$ value of the uncoated Al sample $\left(20.7310^{-6} \Omega^{-1} \mathrm{~s}^{\mathrm{n}} \mathrm{cm}^{-2}\right)$ is higher than that of the graphene-coated substrate $\left(3.7210^{-6} \Omega^{-1} \mathrm{~s}^{\mathrm{n}} \mathrm{cm}^{-2}\right)$, which means there are more reactive sites on uncoated $\mathrm{Al}$ than on graphene-coated $\mathrm{Al}$. The coating capacitance of graphene-coated $\mathrm{Al}$ is 1.19 $\mu \mathrm{F} . \mathrm{cm}^{-2}$ and it is lower than that of uncoated $\mathrm{Al}\left(5.27 \mu \mathrm{F} . \mathrm{cm}^{-2}\right)$.

In order to study the stability of the graphene coating in a saline environment, impedance measurements are particularly useful in long time tests because they do not perturb the system dramatically. The Nyquist impedance diagrams of the graphene-coated sample obtained at different time of immersion in corrosive solution are presented in Fig. 8 (a). The Nyquist plot of uncoated $\mathrm{Al}$ substrate obtained at different time of immersion in $\mathrm{NaCl}(0.5 \mathrm{M})$ are also presented in Fig. 8 (b) in order to facilitate comparison. The shape of the impedance diagrams of coated $\mathrm{Al}$ substrates is similar to those found in the case of uncoated substrates (fig. 8(a) and fig. 8(b)). As seen from figure 8(a), the diameter of the semicircle in the Nyquist plot of graphene-coated $\mathrm{Al}$ substrate increases with immersion time, which means that the impedance of graphene increases with time. This result suggests that the coating forms a very strong protective layer limiting the ion diffusion and providing more protection against corrosion [14, 16, 31]. The equivalent circuits used to fit the experimental data obtained after different time of immersion is the same to that presented in Fig. 7. The corresponding fitting parameters associated with the proposed EEC are listed in Table 2. The corresponding fitting parameters of uncoated aluminum substrate are also presented in Table 3 in order to facilitate comparison.

Qualitatively, the uncoated $\mathrm{Al}$ samples exhibit the same behavior as the coated $\mathrm{Al}$ substrate after exposure in corrosive medium (i.e the total corrosion resistance and the CPE increase with time of immersion in saline environment). However, the total corrosion resistance and CPE of 
$\mathrm{Al}$ substrate were lower than the total corrosion resistance and $\mathrm{CPE}$ of graphene coated $\mathrm{Al}$ substrate.

It is important to note that the total corrosion resistance $\left(R_{1}+R_{2}\right)$ values for coated substrates increase with the time of immersion in the corrosive medium, reaching a maximum value of $199 \mathrm{~K} \Omega . \mathrm{cm}^{2}$ for $360 \mathrm{~h}$ (Table 2). When compared to that obtained for uncoated Al substrates (29 K $\Omega . \mathrm{cm}^{2}$ for $360 \mathrm{~h}$ ) (Table 3), this indicates excellent anti-corrosion performance of graphene-coated Al. This result suggests: (i) the presence of a homogeneous layer with high coverage suppressing the diffusion of ions to the Al substrate, which improves the corrosion resistance; (ii) the graphene layer present high adhesion with the substrate, which protects it even during a long period in a corrosive medium. Furthermore, the coating capacitance decreases with time of immersion. Based on the present EIS results, we can suggest that the graphene nanoplatelets can be considered as an effective barrier layer between the electrolyte (especially against ion chloride diffusion) and the $\mathrm{Al}$ substrate, thus efficiently protecting $\mathrm{Al}$ substrate from corrosion even during a long period.

\section{Structural analysis of graphene coating after immersion in saline environment}

SEM and EDX analysis have been recorded to study the change in surface morphology and composition of uncoated and graphene-coated Al substrates after immersion in corrosive medium. SEM images of the $\mathrm{Al}$ and graphene-coated $\mathrm{Al}$ before and after immersion 2 weeks in $0.5 \mathrm{M} \mathrm{NaCl}$ are presented in Fig. 9. The SEM images show that the uncoated $\mathrm{Al}$ substrate is quite uniform and clean before immersion (Fig. 9 (a)); in particular, rolling marks are clearly visible on the surface. Those rolling marks seem to have disappeared after 2 weeks of immersion in the saline environment (Fig. 9 (b)) and the Al surface is studded with grains, representing oxide particles formed during immersion. On the contrary, the surface of graphenecoated Al shows very little visible change at isolated area (Fig. 9(d)) under the same ageing conditions. Furthermore, the EDX results show that the percentage of oxygen increases from 
0.97 at.\% to 3.84 at.\%, suggesting only small amount of oxide on the graphene-coated $\mathrm{Al}$ surface. Since the thickness of graphene is just several nanometers, the EDX results are not only from graphene but also from the substrate. These results are in agreement with the results obtained from the electrochemical analysis. All these results confirm the high graphene protection of $\mathrm{Al}$ surface in corrosive environment containing chloride ions even during a long time, which, as discussed earlier, is due to its impermeability and chemical inertness.

It is generally admitted that when the aluminum surface is exposed to the atmosphere, a thin oxide/hydroxyde layer forms immediately on top of the surface which is considered as a good protective layer [32]. However, this protective layer comprises about $10^{4} / \mathrm{cm}^{2}$ nanocracks. In a saline environment, the chloride ions adsorb inside the nanocracks of the oxide film, inducing its local breakdown [24]. This provokes the pitting corrosion, as it results in the local dissolution of the unprotected $\mathrm{Al}$ substrate $\left(\mathrm{Al} \rightarrow \mathrm{Al}^{3+}+3 \mathrm{e}^{-}\right.$, Fig.10 (a)). The electrons released by the oxidation of $\mathrm{Al}$ travel through the metal and locally (preferably on impurities) react with water to produce hydrogen $\left(3 \mathrm{H}^{+}+3 \mathrm{e}^{-} \rightarrow 3 / 2 \mathrm{H}_{2}\right)$. Also, the oxygen reduction reaction cannot be neglected $\left(2 \mathrm{H}_{2} \mathrm{O}+\mathrm{O}_{2}+4 \mathrm{e}^{-} \rightarrow 4 \mathrm{OH}^{-}\right)$; the overall reaction is: $\mathrm{Al}+3 \mathrm{H}_{2} \mathrm{O} \rightarrow \mathrm{Al}(\mathrm{OH})_{3}+3 / 2 \mathrm{H}_{2}$. Now, when the $\mathrm{Al}$ is covered by graphene, the access of $\mathrm{Cl}^{-}$ions to the surface oxide/hydroxide is limited. Actually, it has been shown that concerning $\mathrm{Li}^{+}$ions, which are much smaller than $\mathrm{Cl}^{-}$ions (particularly in view of the ionic radii $0.076 \mathrm{~nm}$ for $\mathrm{Li}^{+}$and $0.18 \mathrm{~nm} \mathrm{for} \mathrm{Cl}^{-}$), the critical number of graphene layers necessary to prevent $\mathrm{Li}^{+}$reaching the substrate was $\sim 6$ [33]. Hence, by analogy, we can expect that 4 to 6 layers as we have here will prevent $\mathrm{Cl}^{-}$to reach the $\mathrm{Al}$ surface (Fig.10 (b)).

In order to confirm the graphene inhibition properties, the surface morphology of graphene-coated $\mathrm{Al}$ was evaluated after immersion in another solution containing chloride ions such as $\mathrm{FeCl}_{3}$. We will not elaborate on the overall etching mechanism of $\mathrm{Al}$ by $\mathrm{FeCl}_{3}$, but the $\mathrm{Al}$ still needs to be oxidized to $\mathrm{Al}^{3+}$, meaning that the protective $\mathrm{Al}_{2} \mathrm{O}_{3}$ layer has to be permeated 
by $\mathrm{Cl}^{-}$ion through nanocracks. A scanning electron micrograph of the graphene-coated $\mathrm{Al}$ after $2 \mathrm{~h}$ of exposure in $10^{-3} \mathrm{M} \mathrm{FeCl}_{3}$ is displayed in Fig. 11. The SEM images show that the entire surface of the graphene-coated $\mathrm{Al}$ is undamaged and no attack is observed. This further confirms that graphene is markedly effective in suppressing the access of $\mathrm{Cl}^{-}$ions to the surface of $\mathrm{Al}$.

From electrochemical and structural study, we conclude that the graphene coating preserve the underlying $\mathrm{Al}$ surface under reactive environment over a long time thanks to its impermeability, chemical inertness and good adhesion with the substrate. This coating can be very useful for protection against corrosion in marine environment.

\section{Conclusion}

In summary, the exfoliated graphene nanopletelets provide a good protective coating on $\mathrm{Al}$ foils, even if their thickness is not uniform. The electrochemical characterization indicated that the graphene-coated $\mathrm{Al}$ substrate offers excellent protection against the corrosive medium. The structural characterization recorded after immersion in $0.5 \mathrm{M} \mathrm{NaCl}$ confirms the presence of a graphene layer even 2 weeks of exposure.

\section{Acknowledgements}

This work has benefited from a French government grant managed by ANR within the frame of the national program Investments for the Future ANR-11-LABX-022-01. The authors would also like to acknowledge Dr P. Chatellier (LISIS-COSYS, IFSTTAR-Marne la Vallée) for helpful discussions.

\section{References}


1. N.G. Thompson, M. Yunovich, D. Dunmire, Cost of Corrosion and Corrosion Maintenance Strategies, Corros. Rev. 25 (2007), p. 247-262.

2. D. Prasai, J.C. Tuberquia, R.R. Harl, G.K. Jennings, K.I. Bolotin, Graphene corrosion inhibiting coating, ACS Nano. 6 (2012), p. 1102-1108.

3. J.S. Bunch, S.S. Verbridge, J.S. Alden, A.M. Van der Zande, J.M. Parpia, H.G. Craighead, P.L. McEuen, Impermeable Atomic Membranes from Graphene Sheets. Nano Lett. 8 (2008), p. 2458-2462.

4. Z. Chen, W. Ren, L. Gao, B. Liu, S. Pei, H.M. Cheng, Three dimensional flexible and conductive interconnected graphene networks grown by chemical vapour deposition, Nat. Mater. 10 (2011), p. 424-8.

5. W.A. De Heer, C. Berger, X.S. Wu, P.N. First, E.H. Conrad, X.B. Li, T.B. Li, M. Sprinkle, J. Hass, M.L. Sadowski, et al., Epitaxial Graphene, Solid State Commun. 143 (2007), p. 92100 .

6. J. Hass, F. Varchon, J.E. Millan-Otoya, M. Sprinkle, N. Sharma, W.A. De Heer, C. Berger, P.N. First, L. Magaud, E.H. Conrad, Why Multilayer Graphene on 4H-SiC(0001)

Behaves Like a Single Sheet of Graphene, Phys. Rev. Lett. 100 (2008), p. 125504.

7. L. Liu, S. Ryu, R. Michelle, E. Tomasik, N. Jung, M.S. Hybertsen, M.L. Steigerwald, L. E. Brus, G.W. Flynn, Graphene Oxidation: Thickness-Dependent Etching and Strong Chemical Doping, Nano Lett. 8 (2008), p. 1965-1970.

8. S. Chen, L. Brown, M. Levendorf, W. Cai, S. Ju, J. Edgeworth, et al., Oxidation resistance of graphene - coated $\mathrm{Cu}$ and $\mathrm{Cu} / \mathrm{Ni}$ alloy, ACS Nano. 5 (2011), p. 1321-1327.

9. N.T. Kirkland, T. Schiller, N. Medhekar, N. Birbilis, Exploring graphene as a corrosion protection barrier, Corros Sci. 56 (2012), p. 1-4.

10. P.K. Nayak, C.-J. Hsu, S.-C. Wang, J.C. Sung, J.-L. Huang, Graphene Coated Ni Films: A Protective Coating, Thin Solid Films. 529 (2013), p. 312-316.

11. I. Wlasny, P. Dabrowski, M. Rogala, P.J. Kowalczyk, I. Pasternak, W. Strupin- ski, et al., Role of graphene defects in corrosion of graphene-coated $\mathrm{Cu}\left(\begin{array}{lll}1 & 1 & 1\end{array}\right)$ surface, Appl. Phys. Lett. 102 (2013), p. 111601.

12. A.S. Kousalya, A. Kumar, R. Paul, D. Zemlyanov, T.S. Fisher, Graphene: an effective oxidation barrier coating for liquid and two-phase cooling systems, Corros. Sci. 69 (2013), p. $5-10$. 
13. R.K.S. Raman, P.C. Banerjee, D.E. Lobo, H. Gullapalli, M. Sumandasa, A. Kumar, et al., Protecting copper from electrochemical degradation by graphene coating, Carbon. 50 (2012), p. $4040-4045$.

14. J. Liu, L. Hua, S. Li, M. Yu, Graphene dip coatings: An effective anticorrosion barrier on aluminum, Applied Surface Science. 327 (2015), p. 241-245.

15. P. K. Ghosh, S. Ghosh, I. Basumallick, Electrochemical Studies on Aluminium Corrosion in Dilute Alkaline Dispersions of Graphene Oxide, British Journal of Applied Science Technology. 9 (2015), p. 86-99.

16. Y. Liu, J. Zhang, S. Li, Y. Wang, Z. Han, L. Ren, Fabrication of a superhydrophobic graphene surface with excellent mechanical abrasion and corrosion resistance on an aluminum alloy substrate, RSC Advances. 4 (2014), p. 45389-45396.

17. S.J. Richard Prabakar, Y.H. Hwang, E. G. Bae, D.K. Lee, M. Pyo, Graphene oxide as a corrosion inhibitor for the aluminum current collector in lithium ion batteries, Carbon. 52 (2013), p. $128-136$.

18. Y. Raghupathy, A. Kamboj, M.Y. Rekha, N.P. Narasimha Rao, C. Srivastava, Coppergraphene oxide composite coatings for corrosion protection of mild steel in $3.5 \% \mathrm{NaCl}$, Thin Solid Films. 636 (2017), p. 107-115.

19. J. Mondal, J. Kozlova, V. Sammelselg, Graphene Nanoplatelets Based Protective and Functionalizing Coating for Stainless Steel, Journal of Nanoscience and Nanotechnology. 15 (2015), p. 6747-6750.

20. F. Gao, C. Xu, H. Hub, Q. Wang, Y. Gao, H. Chen, Q. Guo, D. Chen, D. Eder, Biomimetic synthesis and characterization of hydroxyapatite/graphene oxide hybrid coating on $\mathrm{Mg}$ alloy with enhanced corrosion resistance, Materials Letters.138 (2015), p. 25-28.

21. K.C. Chang, M.H. Hsu, H.I. Lu, M.C. Lai, P.J. Liu, C.H. Hsu, W.F. Ji, T.L. Chuang, Y. Wei, J.M. Yeh, W.R. Liu, Room-temperature cured hydrophobic epoxy/graphene composites as corrosion inhibitor for cold-rolled steel, Carbon. 66 (2014), p. 144-153.

22. S.C. Sahu, A.K. Samantara, M. Seth, S. Parwaiz, B.P. Singh, P.C. Rath, B.K. Jena, A facile electrochemical approach for development of highly corrosion protective coatings using graphene nanosheets, Electrochemistry Communications. 32 (2013), p. 22-26.

23. V. M. -Stankovic', I. Jevremovic', I. Jung, K.Y. Rhee, Electrochemical study of corrosion behavior of graphene coatings on copper and aluminum in a chloride solution, Carbon. 75 (2 014), p. $335-344$. 
24. W.A. Badawy, F.M. Al-Khara, A.S. El-Azab, Electrochemical behaviour and corrosion inhibition of Al, Al-6061 and Al-Cu in neutral aqueous solutions, Corros. Sci. 41 (1999), p. 709-727.

25. L. Jiao, B. Fan, X. Xian, Z. Wu, J. Zhang, Z. Liu, Creation of Nanostructures with Poly(methylmethacrylate) -Mediated Nanotransfer Printing, J. Am. Chem. Soc. 130 (2008), p. 12612-12613.

26. A.C. Ferrari, J.C. Meyer, V. Scardaci, C. Casiraghi, M. Lazzeri, F. Mauri, et al., Raman spectrum of graphene and graphene layers, Phys. Rev. Lett. 97 (2006), p. 187401.

27. L.M. Malard, M.A. Pimenta, G. Dresselhaus, M. S. Dresselhaus, Raman Spectroscopy in Graphene, Phys. Rep. 473 (2009), p. 51-87.

28. A. Reina, H.B. Son, L.Y. Jiao, B. Fan, M.S. Dresselhaus, Z.F. Liu, J. Kong, Transferring and Identification of Single and Few-Layer Graphene on Arbitrary Substrates. J. Phys. Chem. C 112 (2008), p. 17741-17744.

29. X. Li, W. Cai, J. An, S. Kim, J. Nah, D. Yang, R. Piner, A. Velamakanni, I. Jung, E. Tutuc, S.K. Banerjee, L. Colombo, R.S. Ruoff, Large-Area Synthesis of High-Quality and Uniform Graphene Films on Copper Foils, Science. 324 (2009), p. 1312-1314.

30. F. Mansfeld, M.W. Kendig, W.J. Lorenz, Corrosion Inhibition in Neutral, Aerated Media, J. Electrochem. Soc. 132 (1985), p. 290-296.

31. S.G. Chen, Y. Chen, Y. H. Lei, Y.S. Yin, Novel strategy in enhancing stability and corrosion resistance for hydrophobic functional films on copper surfaces, Electrochem. Commun. 11 (2009), p. 1675-1679.

32. V.B. Miskovic-Stankovica, M.R. Stanica, D.M. Drazicb, Corrosion protection of Al by a cataphoretic epoxy coating, Prog. Org. Coat. 36 (1999), p. 53-63.

33. F. Yao, F. Güneş, H. Q. Ta, S. M. Lee, S. J. Chae, K. Y. Sheem, C.S. Cojocaru, S. S. Xie, Y.H. Lee, Diffusion Mechanism of Lithium Ion through Basal Plane of Layered Graphene, J. Am. Chem. Soc. 134 (2012), p. 8646-8654. 


\section{Figures captions}

FIGURE 1. Raman spectra of graphene nanoplatelets films on Al substrates, showing the characteristic $D, G$ and $2 D$ peaks.

FIGURE 2. TEM analysis of graphene nanoplatelets originally coating Al foils and transferred onto TEM grids. (a) Low-magnification overall general view of the sample. (b) HRTEM image of the edge, where a local folding allows one to count the number of graphene layers (about four layers thick and exhibiting lateral dimensions larger than a micrometer). (c) Intensity profile of the image in (a), indicating a distance of $1.52 \mathrm{~nm}$ between the graphene layers which corresponds to four layers graphene. (d) Selected area EDP from the white square in (d); the 6fold symmetry shows the crystalline nature of graphene.

FIGURE 3. (a and b) Scanning electron microscopy (SEM) micrographs of an Al foil coated with graphene nanoplatelets.

FIGURE 4. ( $\mathrm{a}$ and $\mathrm{b}$ ) Variations of $\mathrm{OCP}$ of pristine $\mathrm{Al}$ and graphene-coated $\mathrm{Al}$ during 2 weeks of immersion in a $0.5 \mathrm{M} \mathrm{NaCl}$ solution. (a) zoom of the area marked by the black circle in (b) showing the variation of OCP during 30min.

FIGURE 5. (a) The Tafel polarization curves of uncoated $\mathrm{Al}$ and graphene-coated $\mathrm{Al}$ substrates after immersion $264 \mathrm{~h}$ in corrosive medium at $30^{\circ} \mathrm{C}$. (b) Raman spectra of graphene nanoplatlets films after immersion in $\mathrm{NaCl}(0.5 \mathrm{M})$.

FIGURE 6. Nyquist plots of uncoated and graphene-coated $\mathrm{Al}$ foils after $312 \mathrm{~h}$ of immersion in $0.5 \mathrm{M} \mathrm{NaCl}$.

FIGURE 7. ( $\mathrm{a}$ and $\mathrm{b}$ )Bode diagrams of the uncoated $\mathrm{Al}$ and graphene-coated $\mathrm{Al}$ substrates after a $312 \mathrm{~h}$ immersion period in $0.5 \mathrm{M} \mathrm{NaCl}$ at $30^{\circ} \mathrm{C}$. (c) Equivalent electrical circuit (EEC) employed to fit the impedance data of the graphene- coated Al substrate and uncoated $\mathrm{Al}$ substrate in $0.5 \mathrm{M} \mathrm{NaCl}$.

FIGURE 8. (a) Nyquist plots of an $\mathrm{Al}$ foil coated with graphene nanoplatelets at different times of immersion in $0.5 \mathrm{M} \mathrm{NaCl}$. Inset the Nyquist plots of graphene-coated $\mathrm{Al}$ after $360 \mathrm{~h}$ of immersion. (b) Nyquist plots of uncoated $\mathrm{Al}$ substrate at different times of immersion in $0.5 \mathrm{M}$ $\mathrm{NaCl}$.

FIGURE 9. Scanning electron microscopy (SEM) images of Al before (a) and after immersion (b), and graphene- coated $\mathrm{Al}$ before (c) and after (d) immersion 2 weeks in $0.5 \mathrm{M} \mathrm{NaCl}$.

FIGURE10. Schematic of corrosion mechanism of Al substrate (a) and of graphene coated Al (b).

FIGURE11. SEM image of graphene coated $\mathrm{Al}$ substrate after immersion in $\mathrm{FeCl}_{3}\left(10^{-3} \mathrm{M}\right)$. 
Table 1. Fitting results of potentiodynamic curves for uncoated and graphene-coated $\mathrm{Al}$ samples after immersion 11 days in $0.5 \mathrm{M} \mathrm{NaCl}$ at $30^{\circ} \mathrm{C}$.

\begin{tabular}{lcc}
\hline Sample & $\begin{array}{c}\text { Ecorr } v s . \\
S C E(m V)\end{array}$ & $I_{\text {corr }}\left(\mu \mathrm{A} / \mathrm{cm}^{2}\right)$ \\
\hline Uncoated Al & -690 & 0.2 \\
$\begin{array}{l}\text { Graphene } \\
\text { coated Al }\end{array}$ & -672 & 0.07 \\
\hline
\end{tabular}


Table 2. Impedance parameters for graphene coated Al substrate after immersion different times in $0.5 \mathrm{M} \mathrm{NaCl}$.

\begin{tabular}{|c|c|c|c|c|c|c|c|}
\hline $\begin{array}{c}\text { Time of } \\
\text { immersion } \\
\text { (h) }\end{array}$ & $\begin{array}{c}R_{s} \\
\left(\Omega . \mathbf{c m}^{2}\right)\end{array}$ & $\begin{array}{c}R_{1} \\
\left(\mathrm{k} \Omega . \mathrm{cm}^{2}\right)\end{array}$ & $\begin{array}{c}\mathrm{CPE}_{1} \\
\left(10^{6} \Omega^{-1} \mathrm{~s}^{\mathrm{n}} \mathrm{cm}-{ }^{2}\right)\end{array}$ & $\mathbf{n}_{1}$ & $\begin{array}{c}\mathrm{R}_{2} \\
\left(\mathrm{k} \Omega \cdot \mathrm{cm}^{2}\right)\end{array}$ & $\begin{array}{c}\mathrm{CPE}_{2} \\
\left(10^{6} \Omega^{-1} \mathrm{~s}^{\mathrm{n}} \mathrm{cm}-{ }^{2}\right)\end{array}$ & $\mathbf{n}_{2}$ \\
\hline 0.5 & $33.84 \pm 0.01$ & $0.58 \pm 0.01$ & $24.99 \pm 0.03$ & $0.95 \pm 0.003$ & $0.73 \pm 0.01$ & $95.91 \pm 0.01$ & $0.99 \pm 0.001$ \\
\hline 1 & $33.7 \pm 0.02$ & $1.65 \pm 0.01$ & $45.92 \pm 0.02$ & $0.99 \pm 0.001$ & $1.2 \pm 0.02$ & $15.62 \pm 0.02$ & $0.99 \pm 0.002$ \\
\hline 2 & $34.01 \pm 0.01$ & $1.72 \pm 0.02$ & $29.67 \pm 0.02$ & $0.92 \pm 0.002$ & $6.32 \pm 0.01$ & $16.11 \pm 0.01$ & $0.95 \pm 0.005$ \\
\hline 24 & $33.62 \pm 0.01$ & $2.53 \pm 0.03$ & $2.51 \pm 0.01$ & $0.99 \pm 0.001$ & $7.21 \pm 0.01$ & $6.75 \pm 0.02$ & $0.94 \pm 0.001$ \\
\hline 48 & $33.48 \pm 0.01$ & $10.22 \pm 0.09$ & $2.32 \pm 0.04$ & $0.92 \pm 0.004$ & $21.10 \pm 0.02$ & $4.03 \pm 0.01$ & $0.9 \pm 0.002$ \\
\hline 168 & $33.51 \pm 0.01$ & $11.55 \pm 0.01$ & $2.21 \pm 0.01$ & $0.99 \pm 0.002$ & $22.53 \pm 0.03$ & $4.23 \pm 0.02$ & $0.89 \pm 0.001$ \\
\hline 312 & $33.43 \pm 0.02$ & $15.28 \pm 0.02$ & $2.05 \pm 0.02$ & $0.95 \pm 0.001$ & $22.82 \pm 0.01$ & $3.87 \pm 0.01$ & $0.98 \pm 0.003$ \\
\hline 336 & $33.18 \pm 0.01$ & $27.88 \pm 0.04$ & $0.29 \pm 0.02$ & $0.98 \pm 0.002$ & $79.95 \pm 0.02$ & $0.79 \pm 0.02$ & $0.98 \pm 0.002$ \\
\hline 360 & $33.81 \pm 0.01$ & $49.89 \pm 0.09$ & $0.15 \pm 0.02$ & $0.99 \pm 0.002$ & $149.59 \pm 0.01$ & $0.03 \pm 0.01$ & $0.99 \pm 0.001$ \\
\hline
\end{tabular}

Table 3. Impedance parameters for uncoated $\mathrm{Al}$ substrate after immersion different times in 0.5 $\mathrm{M} \mathrm{NaCl}$.

\begin{tabular}{cccccccc}
\hline $\begin{array}{c}\text { Time of } \\
\text { immersion } \\
(\mathrm{h})\end{array}$ & $\begin{array}{c}\mathrm{Rs} \\
(\Omega . \mathrm{cm} 2)\end{array}$ & $\begin{array}{c}\mathrm{R} 1 \\
(\mathrm{k} \Omega . \mathrm{cm} 2)\end{array}$ & $\begin{array}{c}\mathrm{CPE} 1 \\
(106 \Omega-1 \mathrm{sncm}-\end{array}$ & $\mathrm{n} 1$ & $\begin{array}{c}\mathrm{R} 2 \\
(\mathrm{k} \Omega . \mathrm{cm} 2)\end{array}$ & $\begin{array}{c}\text { CPE2 } \\
(106 \Omega-1 \mathrm{sncm}-\end{array}$ & $\mathrm{n} 2)$ \\
\hline 0.5 & & & $2)$ & & & & \\
& & & & & & & \\
1 & $33.01 \pm 0.01$ & $0.34 \pm 0.21$ & $123.19 \pm 0.01$ & $0.5 \pm 0.001$ & $0.52 \pm 0.04$ & $165.91 \pm 0.02$ & $0.59 \pm 0.001$ \\
2 & $33.25 \pm 0.02$ & $2.62 \pm 0.05$ & $30.05 \pm 0.02$ & $0.61 \pm 0.003$ & $4.64 \pm 0.03$ & $53.01 \pm 0.01$ & $0.65 \pm 0.003$ \\
24 & $33.54 \pm 0.01$ & $3.26 \pm 0.05$ & $12.54 \pm 0.03$ & $0.55 \pm 0.005$ & $4.79 \pm 0.03$ & $35.2 \pm 0.01$ & $0.63 \pm 0.001$ \\
48 & $33.49 \pm 0.01$ & $3.94 \pm 0.43$ & $12.27 \pm 0.01$ & $0.65 \pm 0.003$ & $5.10 \pm 0.02$ & $31.1 \pm 0.02$ & $0.5 \pm 0.003$ \\
168 & $34.32 \pm 0.01$ & $4.54 \pm 0.81$ & $12.01 \pm 0.02$ & $0.61 \pm 0.002$ & $5.21 \pm 0.01$ & $25.1 \pm 0.03$ & $0.59 \pm 0.001$ \\
312 & $34.15 \pm 0.02$ & $4.66 \pm 0.79$ & $11.24 \pm 0.05$ & $0.62 \pm 0.001$ & $5.36 \pm 0.03$ & $20.73 \pm 0.02$ & $0.63 \pm 0.002$ \\
336 & $33.68 \pm 0.01$ & $5.18 \pm 0.06$ & $6.21 \pm 0.01$ & $0.65 \pm 0.002$ & $8.93 \pm 0.05$ & $19.76 \pm 0.03$ & $0.67 \pm 0.002$ \\
360 & $33.12 \pm 0.01$ & $10.68 \pm 0.79$ & $5.01 \pm 0.03$ & $0.64 \pm 0.001$ & $19.05 \pm 0.02$ & $19.02 \pm 0.01$ & $0.62 \pm 0.003$
\end{tabular}




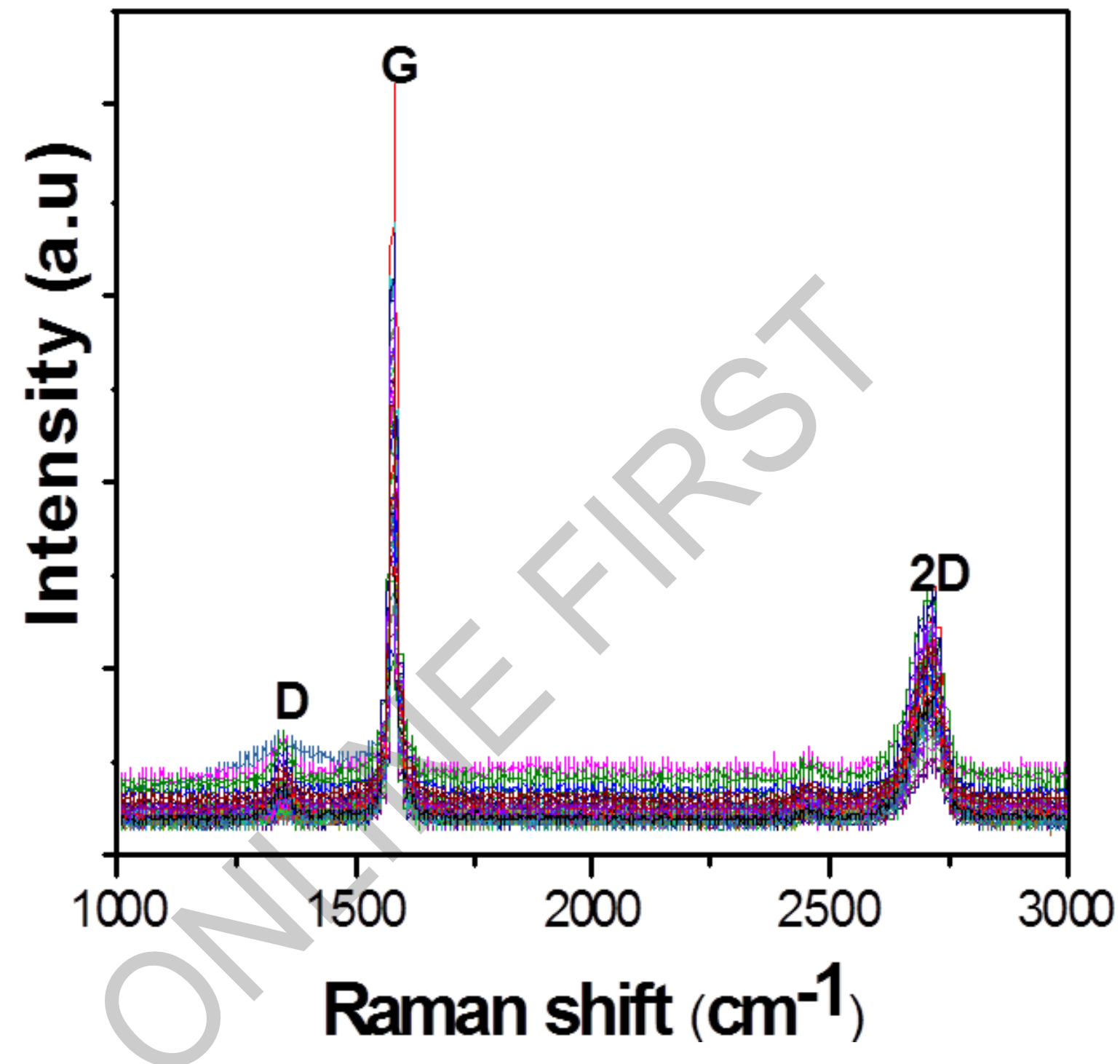

FIGURE 1. 


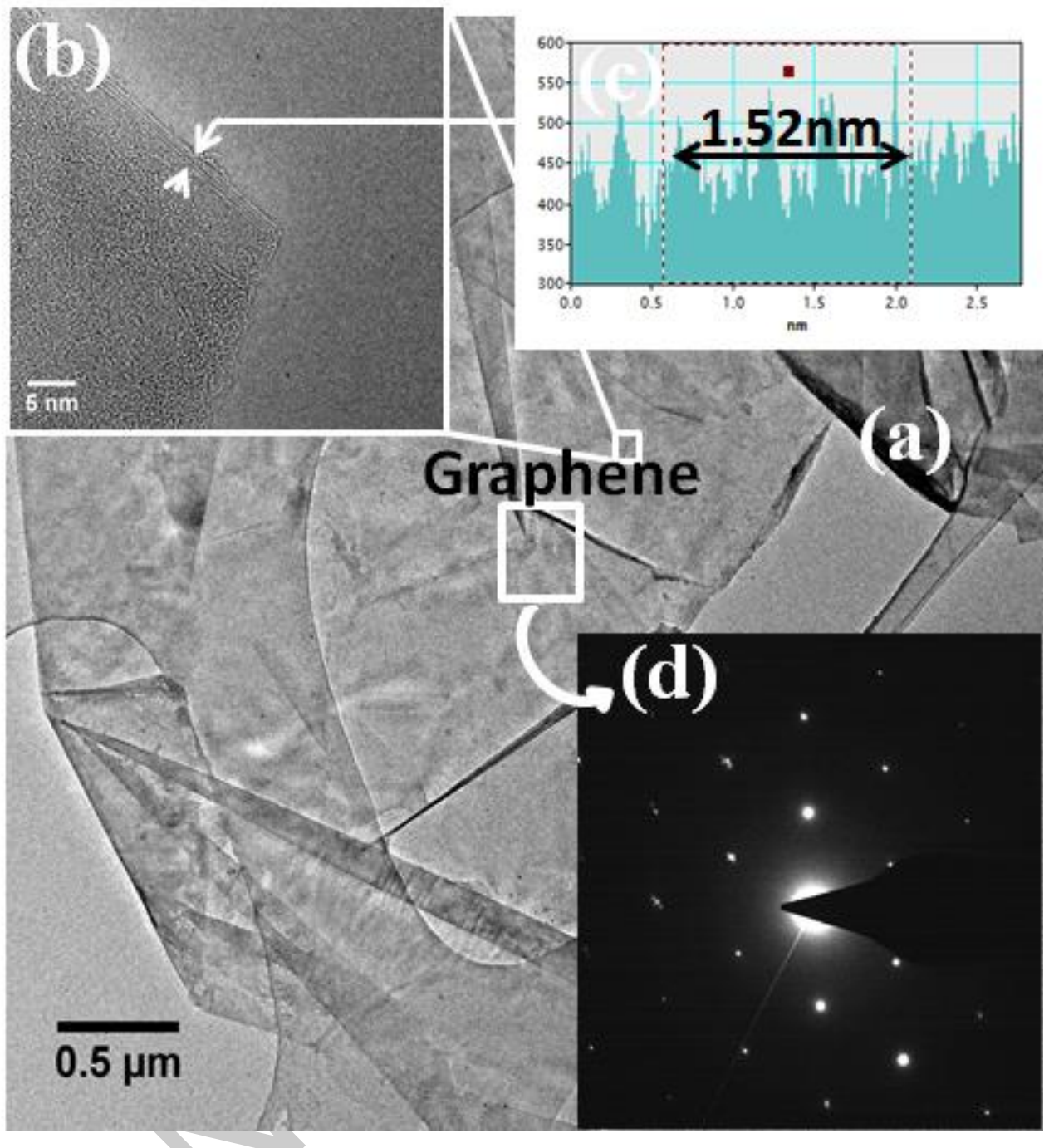

FIGURE 2. 

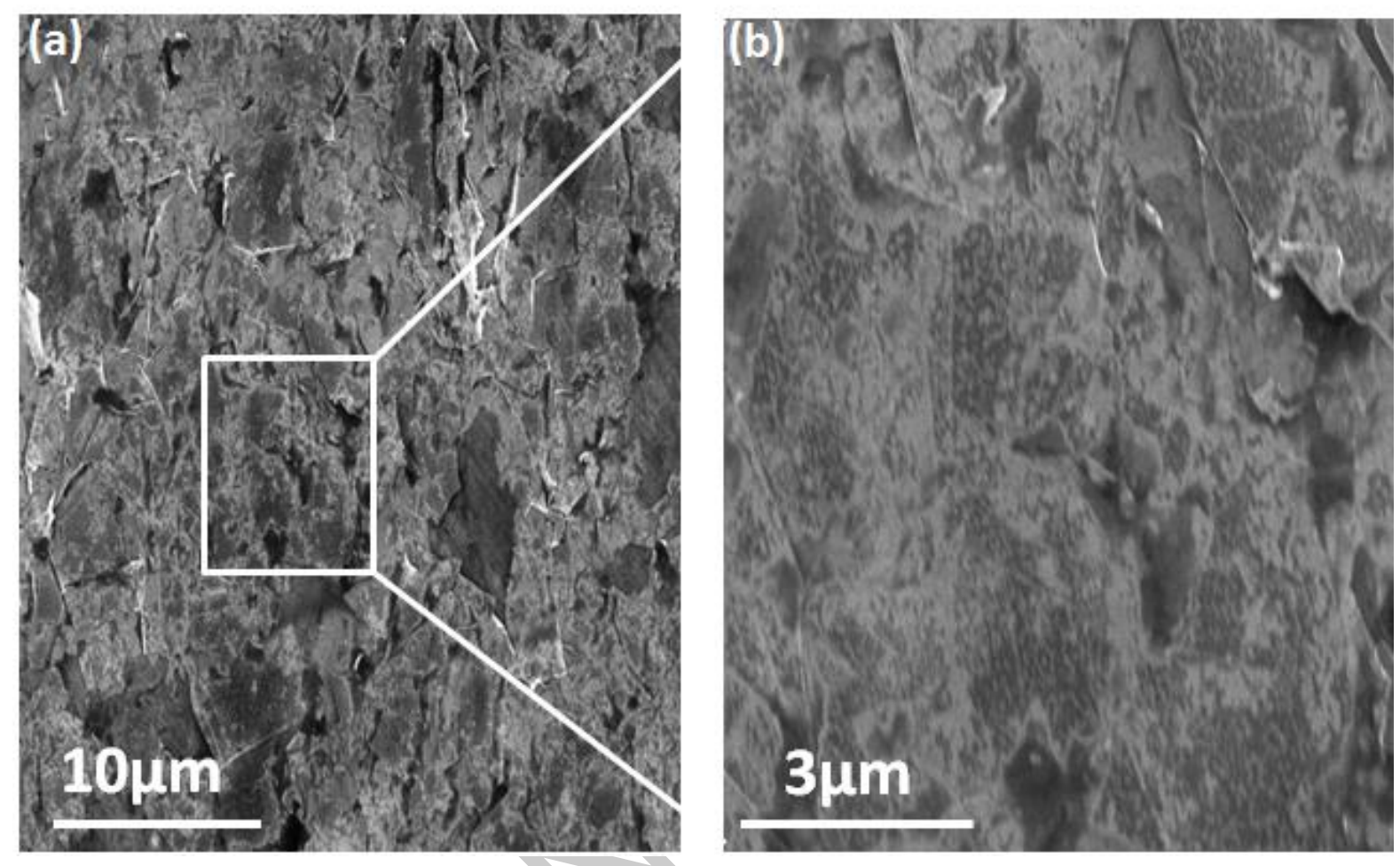

FIGURE 3. 


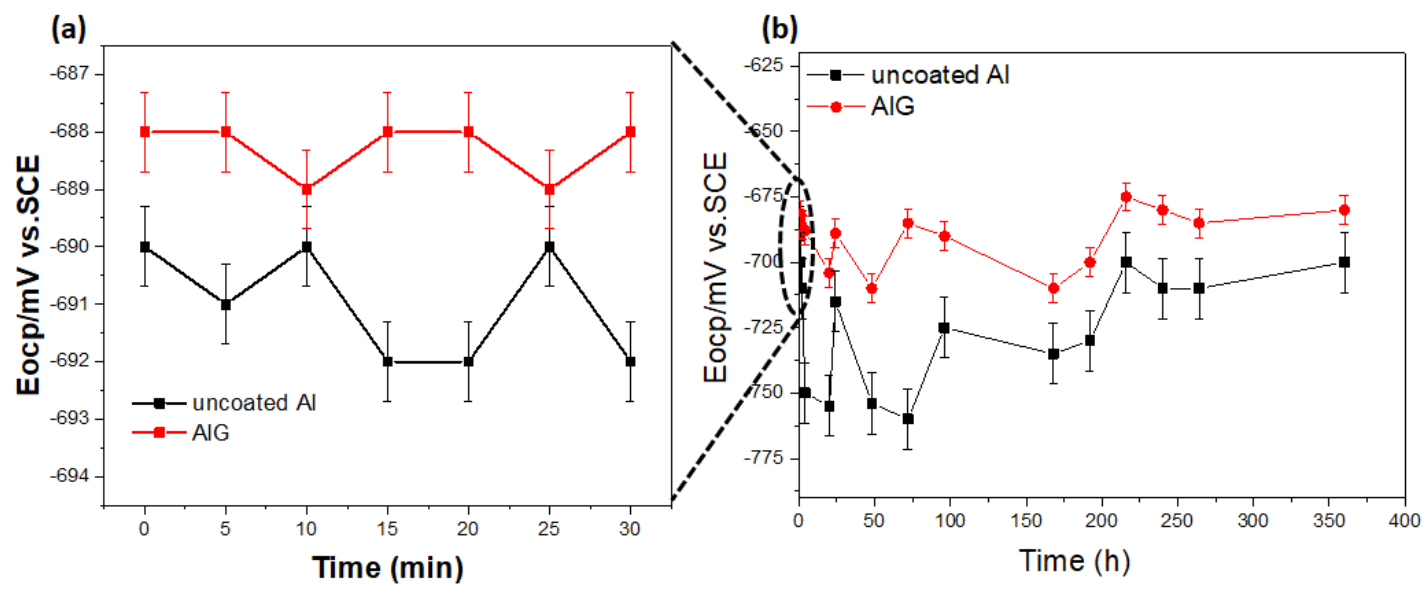

FIGURE 4. 

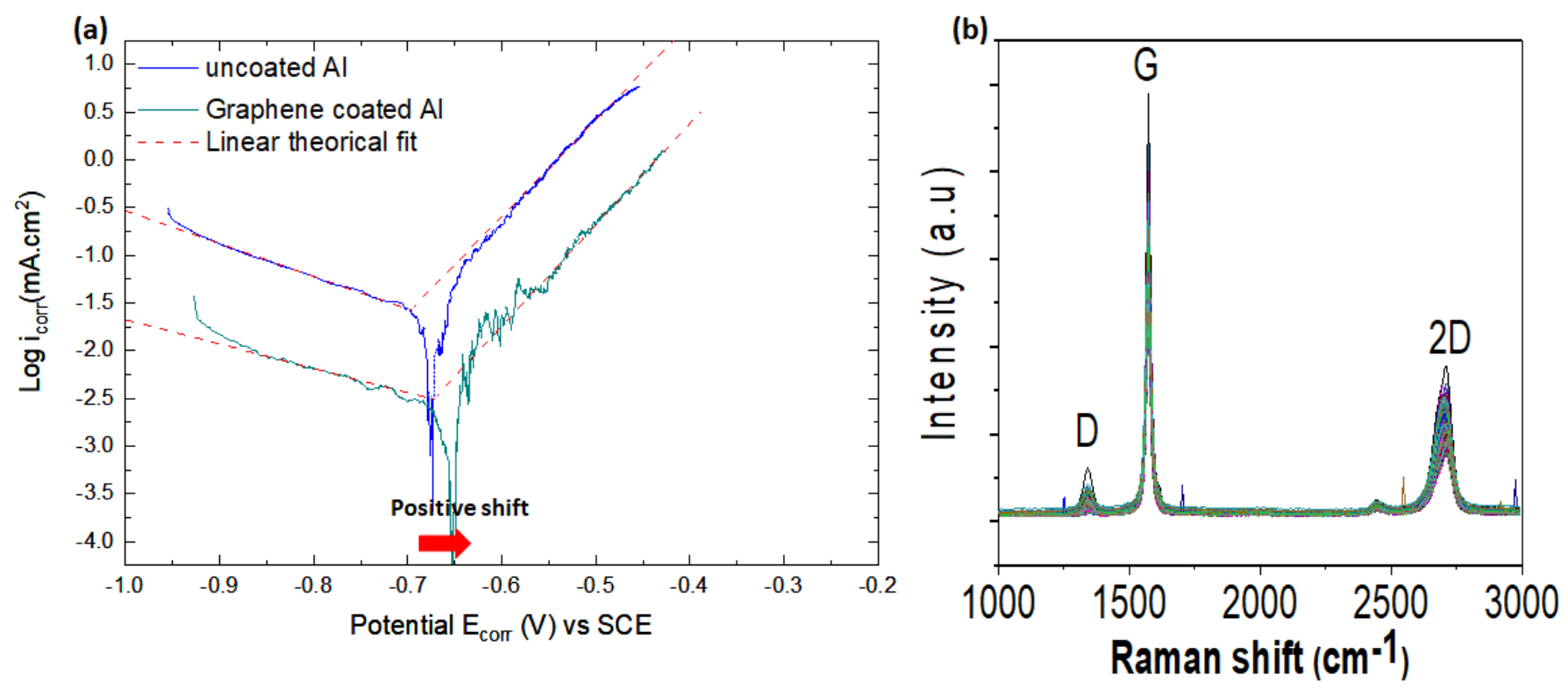

FIGURE 5. 


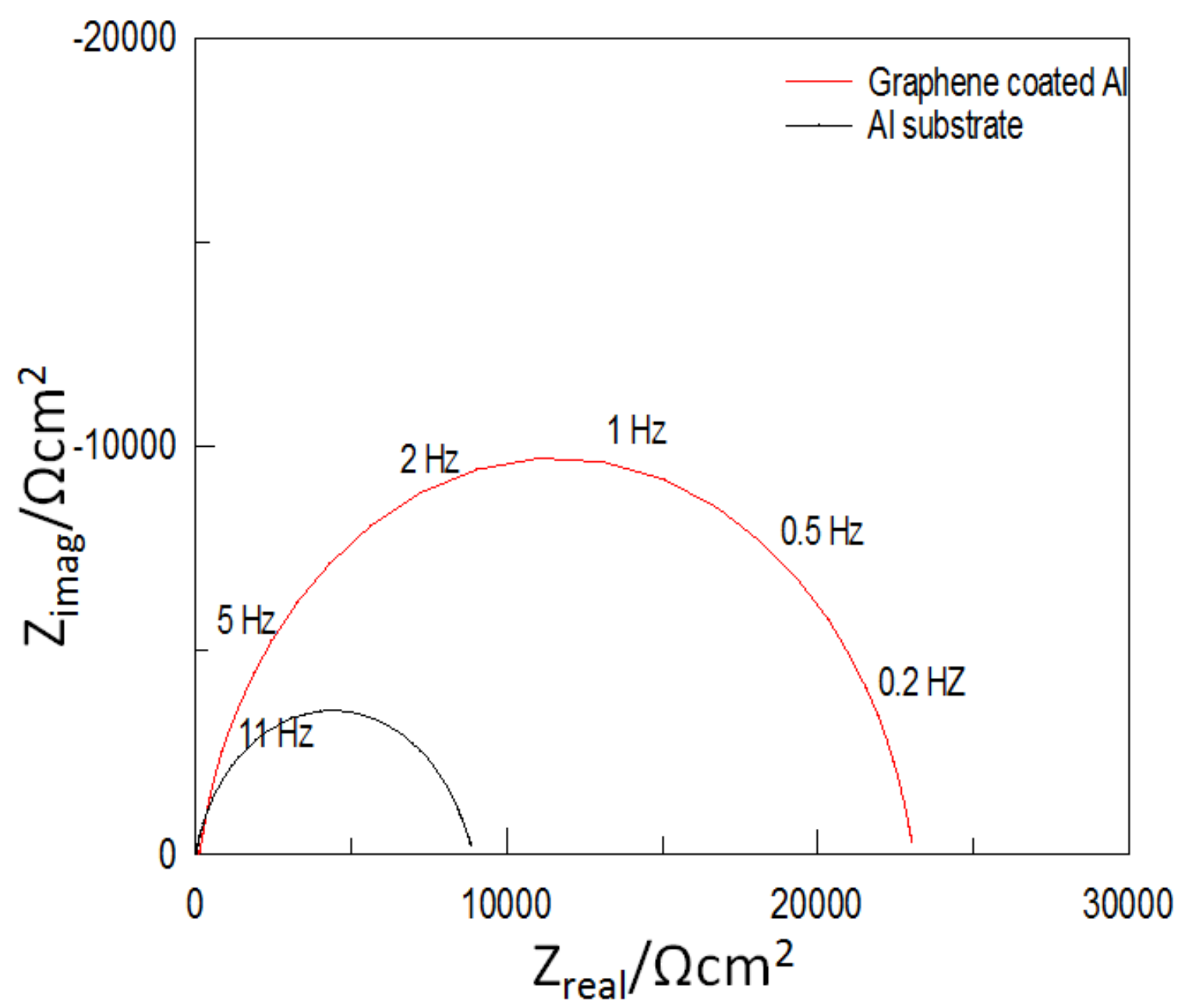

FIGURE 6. 


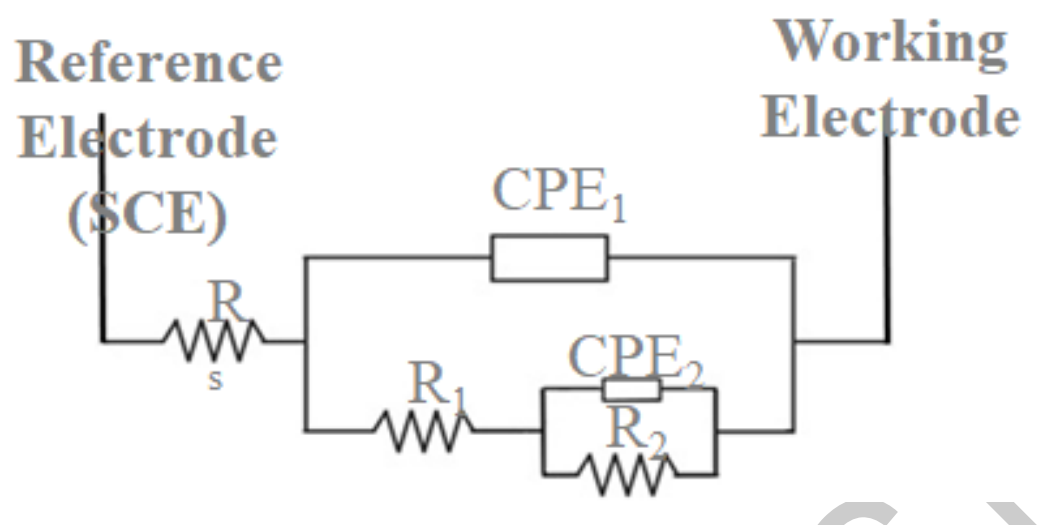

FIGURE 7 

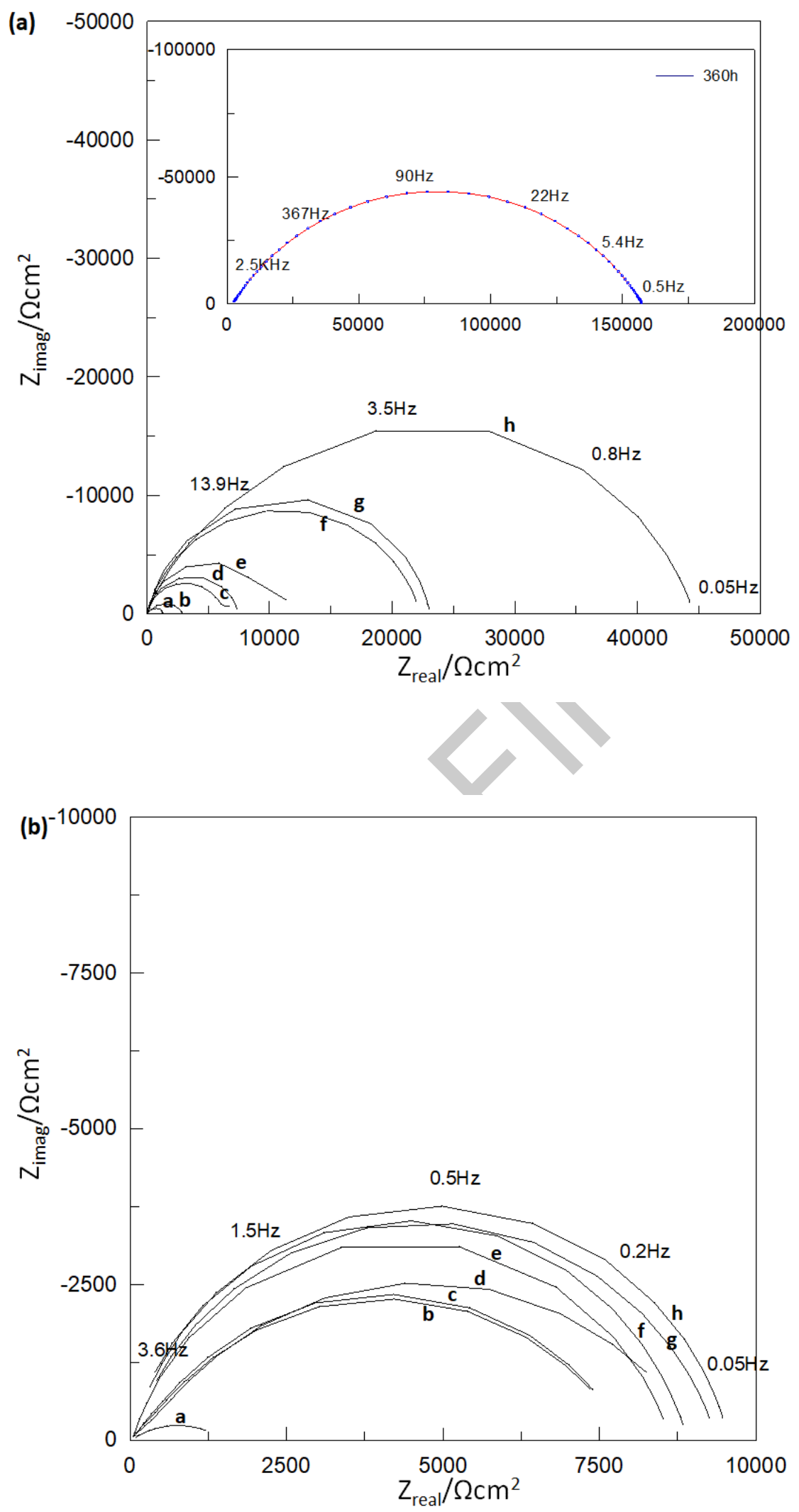

Figure 8 

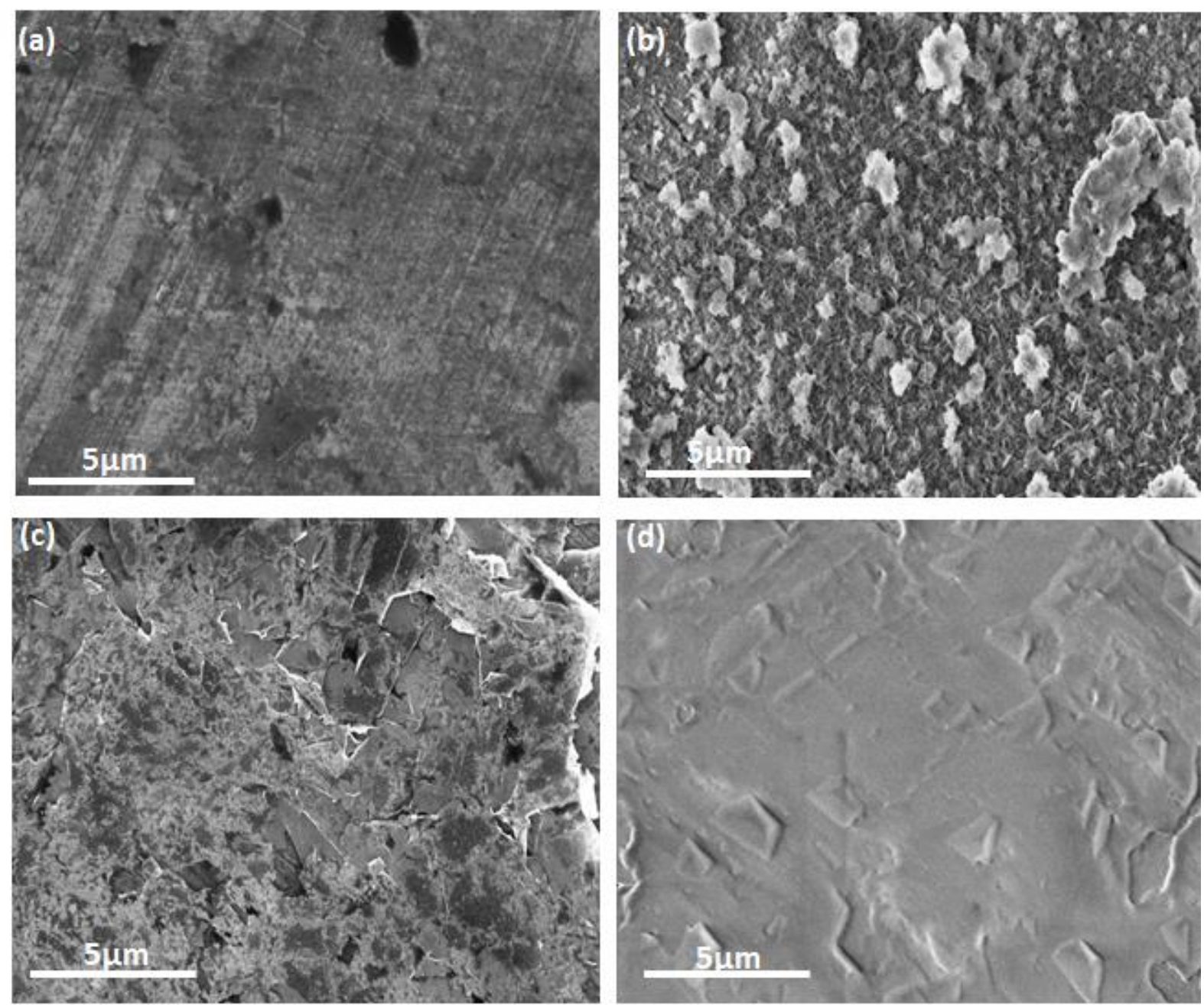

FIGURE 9. 
(a)

(b)
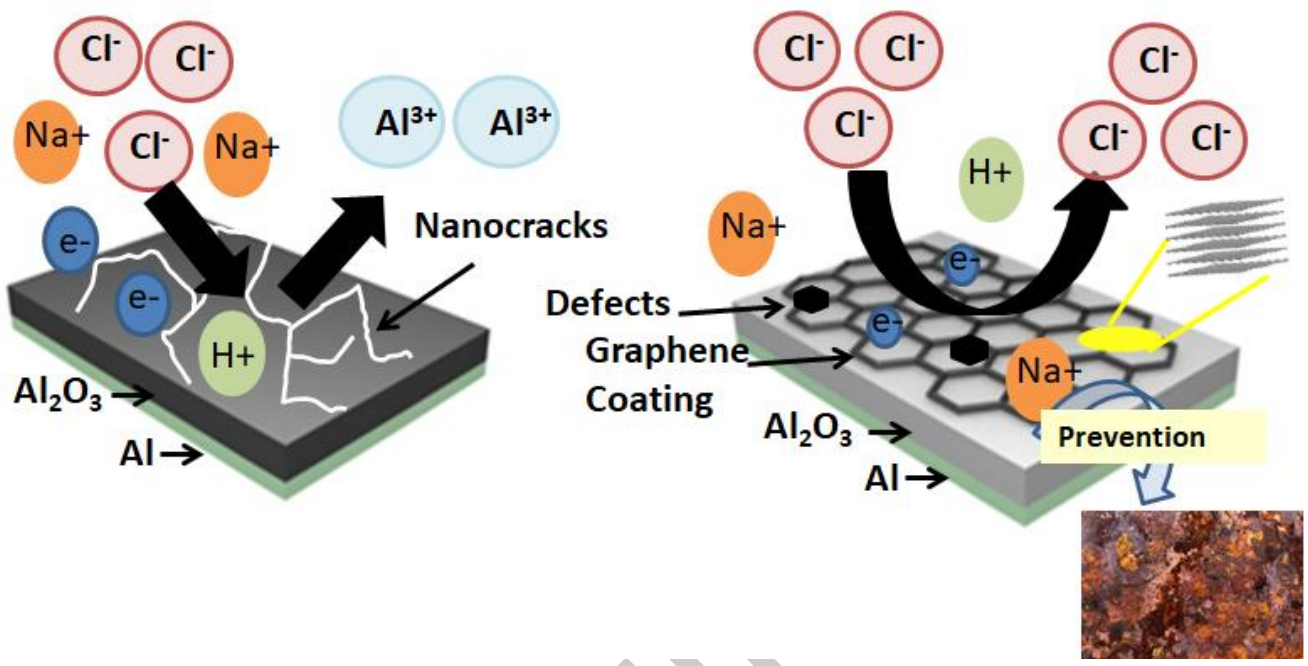

FIGURE 10. 

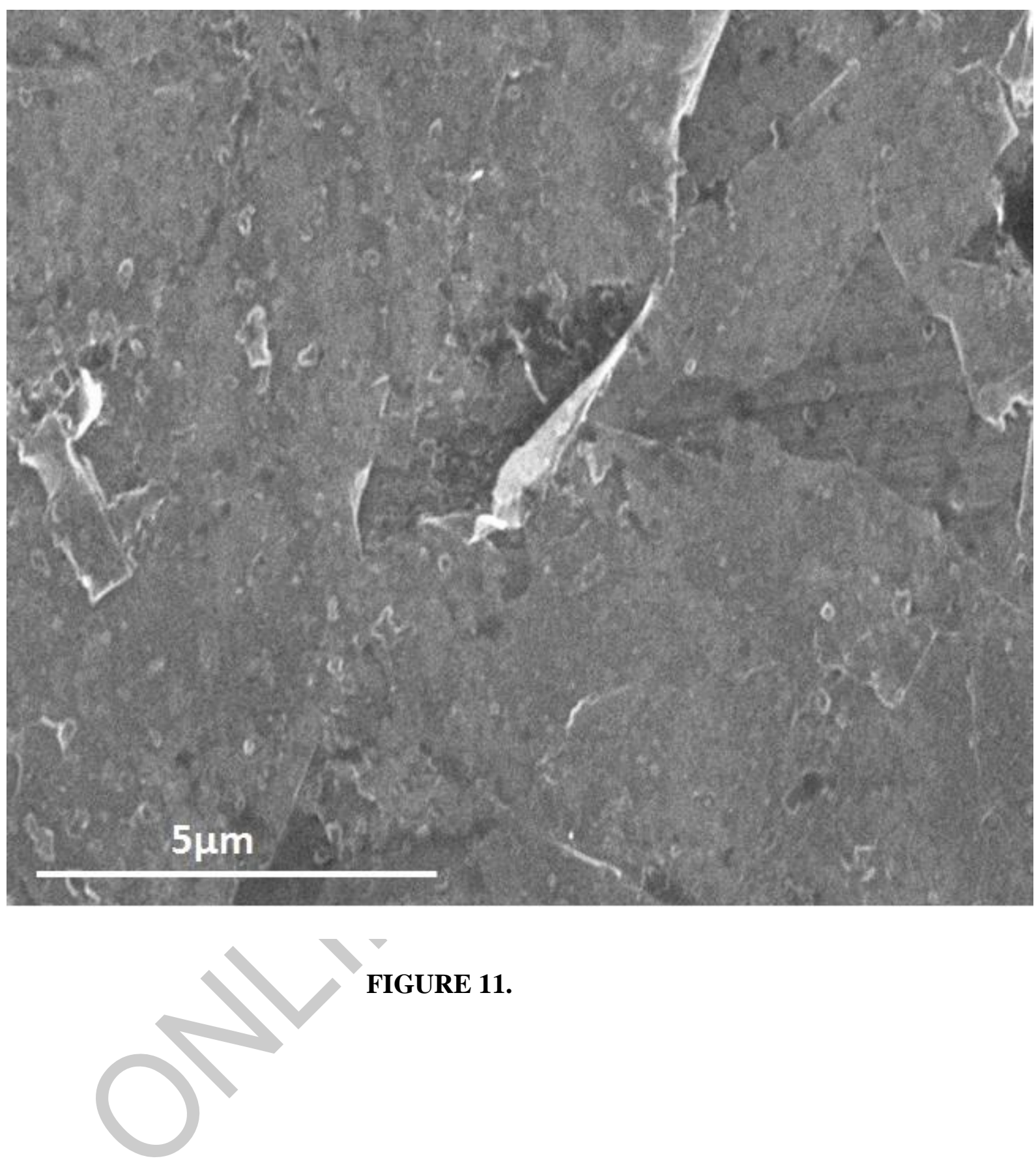

FIGURE 11. 